\title{
MEDIASTINAL AND MULTICENTRIC LYMPHOSARCOMA IN A CAT WITH 8 MONTHS YEARS OLD - CASE REPORT
}

\author{
DE NARDI, A.B. ${ }^{1}$; RODASKI, S. ${ }^{2}$; SOUSA, R.S. ${ }^{2}$; GUÉRIOS, S.D. ${ }^{2}$ \\ ${ }^{1}$ Graduando de Medicina Veterinária da Universidade Federal do Paraná; \\ ${ }^{2}$ Departamento de Medicina Veterinária da Universidade Federal do Paraná.
}

Lymphosarcoma accounts for up to $90 \%$ of the hematopoietc tumors in canines and felines with higher incidence in cats, with an estimated of 200 cases/ 1.000 .000 cats at risk. Lymphosarcoma that follows infection with the feline leukemia virus usually develops the tumors in 2 years old cats. The present case report has the objective to report a mediastinal and multicentric lymphosarcoma in a 8 month old cat. An 8 months old male, not neutered cat was taken to the UFPR Veterinary Hospital because its apathy, anorexia and exercise intolerance observed in the preceeding week. It was observed decreased in lungs sounds, and at palpation test it was observed a mat sound. Because the patient's bad condition the owner did not authorize complementary exams for the diagnosis and opted for euthanasia. At the necropsy it was observed a cancer at cranial and caudal mediastinal, liver and spleen. The histophatologic exam showed a mediastinal lymphosarcoma with hepatic and splenic involvement. In conclusion, lymphoid tumors in cats can develop in young animals, however the literature accounts them for older animals.

Key Words: lymphosarcoma, thoracic neoplasm, cat. 